\title{
Corpo e Alma em Foucault: Postulados PARA UMA METODOLOGIA DA PSICOLOGIA ${ }^{1}$
}

\author{
Fernando de Almeida Silveira ${ }^{2}$ e Reinaldo Furlan ${ }^{3}$ \\ Faculdade de Filosofia, Ciências e Letras de Ribeirão Preto - USP
}

\begin{abstract}
Michel Foucault destaca o corpo como expressão de poderes e de saberes que se articulam estrategicamente na história da sociedade ocidental. $O$ corpo é, simultaneamente, agente e peça dentro de um jogo de forças presente em toda a rede social, que o torna depositário de marcas e de sinais que nele se inscrevem nesses embates, os quais, por sua vez, têm na corporeidade seu "campo de prova". E a alma surge como instrumento de atuação dos poderes/saberes sobre o corpo, no processo de constituição do corpo histórico dos sujeitos. O objetivo deste trabalho é desenvolver postulados sobre o corpo e a alma em Foucault, para o estudo e a prática da Psicologia.
\end{abstract}

Descritores: Foucault, Michel, 1926-1984. Corpo. Alma. Subjetivação.

processo histórico de constituição do sujeito moderno teve em Foucault um dos seus principais pesquisadores. De sua Arqueologia, dedicada ao estudo das regras discursivas de formação do saber, à sua

1 Esse trabalho originou-se de uma parte da dissertação de mestrado de Fernando de Almeida Silveira, defendida em 2001, no Departamento de Psicologia e Educação da FFCL, Ribeirão Preto - USP, com financiamento da FAPESP.

2 Doutorando em Psicologia, na área de Fundamentos Históricos e Epistemológicos da Psicologia, Departamento de Psicologia e Educação - USP - Ribeirão Preto. Endereço para correspondência: Departamento de Psicologia e Educação. Av. Bandeirantes, 3900, CEP 14040-901. Endereço eletrônico: fesilvey@usp.br

3 Endereço para correspondência: Departamento de Psicologia e Educação. Av. Bandeirantes, 3900, CEP 14040-901. Endereço eletrônico: reinaldof@ffclrp.usp.br 
Genealogia, dedicada às relações constitutivas entre poder, saber e corpo, estava implicada a constituição histórica do sujeito. Com a primeira, Foucault investigou a posição e formação do sujeito do conhecimento, por meio das regras discursivas do saber; com a segunda, sua posição e formação, por meio das práticas sociais. Nesse sentido, em que pese certa dose de retrospectivismo, Foucault não é de todo insensato quando diz que, antes de tudo, foi o sujeito, e não o poder, o tema geral de suas pesquisas (Defert \& Ewald, 1994, p. 223).

Nosso trabalho se focalizará, principalmente, na genealogia foucaultiana, destacando e analisando desta etapa as disposições do corpo atravessado pelos poderes e pelos saberes, enquanto elemento fundamental no processo de subjetivação do homem moderno. Como resultado destas investigações, apresentaremos um conjunto de postulados sobre o corpo e sobre a alma em Foucault, para uma metodologia de estudo e da prática da Psicologia.

\title{
O pressuposto ou descoberta do corpo na genealogia de Michel Foucault
}

\author{
Para Foucault, o poder
}

intervém materialmente, atingindo a realidade mais concreta dos indivíduos - o seu corpo - e que se situa ao nível do próprio corpo social, e não acima dele, penetrando na vida cotidiana e por isso podendo ser caracterizado como micropoder ou sub-poder (Machado, 1979, p. xii).

Esta perspectiva é constantemente direcionada para o desenvolvimento daquilo que se configurou como sendo a "microfísica do poder", ou seja, o foco na corporeidade de cada indivíduo - com seus hábitos, instintos, pulsões, sentimentos, emoções, impulsos e vicissitudes como o ponto fundamental sobre o qual atua um emaranhado complexo de uma série de lutas e de confrontos inerentes a tais saberes, no processo de produção de poder. 
Dentre tais práticas, podemos enumerar, ilustrativamente, os suplícios, as disciplinas, as disposições do corpo no tempo e no espaço, os métodos de auto-exame e de controle, os mecanismos pan-ópticos de vigilância, os atos e as práticas confessionais (de cunho religioso ou científico), a confecção de laudos periciais e psicológicos sobre as disposições corpóreo-anímicas, os exames médicos (que esquadrinham tanto o corpo como a alma dos pacientes, dos loucos, dos excluídos), conceitos de higiene física e de demografia.

É este conjunto de constatações que se configura como uma nova fase do seu projeto histórico-filosófico: a fase genealógica, "um diagnóstico que se concentra nas relações de poder, saber e corpo na sociedade moderna" (Dreyfus \& Rabinow, 1995, p. 117).

Esta fase é representada, principalmente, por Vigiar $e$ Punir (1975/1996), um estudo que se volta para a constituição dos mecanismos de poder/saber, por meio da prática penal/punitiva e do implemento de fórmulas genéricas de dominação, de cunho disciplinar e de vigilância, presentes em toda a sociedade moderna; e por História da Sexualidade I: A Vontade de Saber (1976/1988), em que Foucault mostra a implementação do dispositivo da sexualidade.

Desta maneira, a genealogia foucaultiana foi se revelando como portadora de uma nova estrutura analítica de produção histórico-filosófica, porque reconhece a validade do estudo da corporeidade no que nela se manifesta como mais "próximo", também denominada de "história efetiva" (nitidamente de inspiração nietzscheana): "a história 'efetiva' (...) lança seus olhares ao que está próximo: o corpo, o sistema nervoso, os alimentos e a digestão, as energias; ela perscruta as decadências" (Machado, 1979, p. 29).

E esta apropriação dos aspectos relegados da corporeidade instaura uma verdadeira "vivificação" da filosofia do corpo. Neste sentido, sua criação intelectual é "multi-sensorial": valoriza na filosofia as emanações físico-sensórias do corpo e as eleva a condições de "detentores de história".

Assim sendo, ao focalizar suas investigações no contexto das singularidades próprias da corporeidade, Foucault passa a relevar como 
história os eventos e marcas desta corporeidade, os quais, a princípio, são comumente considerados como "não possuindo história, os sentimentos, o amor, a consciência, os instintos" (Machado, 1979, p. 15) e passa a rastreálos por meio de um estudo minucioso, revelando-os enquanto apropriados por uma complexa série de articulações estratégicas de saberes e de poderes, os quais utilizam o corpo como seu alvo e, mais do que isto, como seu começo.

Nas palavras de Foucault:

O corpo: superfície de inscrição dos acontecimentos (enquanto que a linguagem os marca e as idéias os dissolvem), lugar de dissolução do Eu (que supõe a quimera de uma unidade substancial), volume em perpétua pulverização. A genealogia (...) está portanto no ponto de articulação do corpo com a história. Ela deve mostrar o corpo inteiramente marcado de história e a história arruinando o corpo (Machado, 1979, p. 22).

Em outros termos, o corpo é o campo (porque as forças atravessam e constituem a realidade corpórea, não há força sem corpo) de forças múltiplas, convergentes e contraditórias, e o próprio lugar da sedimentação de seus combates.

Ou ainda,

... sobre o corpo se encontra o estigma dos acontecimentos passados do mesmo modo que dele nascem os desejos, os desfalecimentos e os erros; nele também eles se atam e de repente se exprimem, mas nele também eles se desatam e entram em luta, se apagam uns aos outros e continuam seu insuperável conflito (p. 22).

Ou seja,

... Lá onde a alma pretende se unificar, lá onde o Eu inventa para si uma identidade ou uma coerência, o genealogista parte em busca do começo - dos começos inumeráveis (...) A marca da proveniência permite dissociar o Eu e fazer pulular nos lugares e recantos de sua síntese vazia, mil acontecimentos agora perdidos (p. 20).

Este caráter dissociativo do eu, com seus começos inumeráveis, múltiplos e dissociadores, possibilita a compreensão de uma dinâmica desse 
eu na qual corpo e alma estão submetidos a processos múltiplos de constituição histórica.

Corpo e alma, portanto, são interpenetrados de história e articulados através de diferentes contextos discursivos, os elementos co-construtores de múltiplos focos de subjetivação, de forma que se torna imprescindível associá-los ao processo de edificação da própria identidade histórica do indivíduo.

Dentro deste universo, no qual poder e saber estão intimamente ligados, o que se frisa, portanto, é que "não há constituição de poder sem constituição correlata de um campo de saber, nem saber que não suponha e não constitua, ao mesmo tempo, relações de poder" (Foucault, 1975/1996, pp. 29-30).

Com isto, supera-se a "neutralidade" difusamente presente em diversos grupos intelectuais, de que "fazer ciência não é fazer política", ou a concepção na qual a ciência está dissociada de qualquer disputa pelo poder.

Muito pelo contrário, ao reconhecer o liame estreito entre saber/poder, Foucault lança a ciência e todos os saberes (os quais reconstroem e rearticulam o binômio secular do corpo e da alma) a uma relação de suporte teórico e epistemológico de múltiplos interesses, inerentes aos rearranjos das conformações de poderes imanentes a cada momento em nossa sociedade.

Daí sua analítica dos saberes científicos ter se desdobrado sobre uma vasta diversidade de campos do saber, tais como: a Medicina, o Direito, a Sociologia, a Linguística, a Psicologia, a Demografia, a Pedagogia, a Biologia, a Economia, a Política, a Filosofia, a Sexualidade, todos eles analisados através de uma perspectiva eminentemente histórica.

\section{A constituição histórica do corpo ou a encarnação da alma}

Foucault busca construir a genealogia de uma série de conceitos, construídos ao redor do corpo e a ele acessados, através dos posicionamentos discursivos historicamente constituídos. 
Em outras palavras, busca dissecar o alcance de tais discursos sobre os corpos dos indivíduos, tomados enquanto mecanismos gerais de dominação, de controle, submissão, docilidade, utilidade e normalização de condutas, dispersos anonimamente em toda a rede social, almejando acentuar, assim, o vínculo existente entre o binômio corpo/alma e a díade saber/poder.

Com tal enfoque, Foucault "destrona" a alma de sua compleição metafísica ou divina, ou como entidade abstrata e parte da natureza ahistórica do homem. A alma é elemento focal diretamente produzido junto ao exercício de saber/poder sobre o corpo. O corpo é "superfície de inscrição para o poder, com a semiologia por instrumento; a submissão dos corpos pelo controle das idéias" (Foucault, 1975/1996, p. 93).

Portanto, não se trata de conceber, conforme certas correntes da metafísica clássica, uma alma dissociada do corpo em um processo dualista de relação, mas sim, uma noção de alma criada diretamente sobre o corpo, em função dos interesses políticos sobre ele concentrados.

Em síntese, Foucault considera "a alma, efeito e instrumento de uma anatomia política: a alma, prisão do corpo" (p. 30, grifos nossos).

Desta maneira, ao inverter a clássica proposição platônica quanto ao binômio corpo/alma (lembremos, para Platão, o corpo é a prisão da alma), Foucault desnuda o elemento anímico de seu suposto caráter mitificador ou transcendental, pois faz da alma o foco de atuação do poder/saber sobre o corpo - a alma do delinqüente, do louco, do aprisionado, do sexualizado, por exemplo -, enquanto elemento discursivo-semiótico para o acesso e o exercício dessas forças sobre ele.

Neste contexto, para Foucault (1975/1996), a alma moderna é "o correlativo atual de uma certa tecnologia do poder sobre o corpo" (p. 31). Vale a pena retomar e citar essa bela passagem, onde Foucault descreve o estatuto da alma moderna:

Não se deveria dizer que a alma é uma ilusão, ou um efeito ideológico, mas afirmar que ela existe, que tem uma realidade, que é produzida permanentemente, em torno, na superfície, no interior do corpo pelo funcionamento de um poder que se exerce sobre os que são punidos - de uma maneira geral sobre os que são vigiados, 
treinados e corrigidos, sobre os loucos, as crianças, os escolares, os colonizados, sobre os que são fixados a um aparelho de produção e controlados durante toda a existência. Realidade histórica dessa alma, que, diferentemente da alma representada pela teologia cristã, não nasce faltosa e merecedora de castigo, mas nasce antes de procedimentos de punição, de vigilância, de castigo e de coação. Esta alma real e incorpórea não é absolutamente substância; é o elemento onde se articulam os efeitos de um certo tipo de poder e a referência de um saber, a engrenagem pela qual as relações de poder dão lugar a um saber possível, e o saber reconduz e reforça os efeitos de poder. Sobre essa realidade-referência, vários conceitos foram construídos e campos de análise foram demarcados: psique, subjetividade, personalidade, consciência, etc.; sobre ela técnicas e discursos científicos foram edificados; a partir dela, valorizaram-se as reivindicações morais do humanismo. Mas não devemos nos enganar: a alma, ilusão dos teólogos, não foi substituída por um homem real, objeto de saber, de reflexão filosófica ou de intervenção técnica. O homem de que nos falam e que nos convidam a liberar já é em si mesmo o efeito de uma sujeição bem mais profunda que ele. Uma 'alma' o habita e o leva à existência, que é ela mesma uma peça no domínio exercido pelo poder sobre o corpo. A alma, efeito e instrumento de uma anatomia política; a alma, prisão do corpo. (pp. 31-32)

Em síntese, realidade da alma como uma produção sócio-históricacultural, através do desenvolvimento de uma série de discursos e saberes, que só têm significado materializados no corpo, em instituições e em práticas sociais.

É adesiva aos corpos e comportamentos, mas enquanto realidade histórico-discursiva.

É esta abordagem sócio-histórica do corpo e da alma que consideramos enriquecedora do contexto psicológico, como instrumental para renovadas formas de intervenção e de articulação de resistências.

\section{Um exemplo de genealogia: o cristianismo e a psicanálise}

A crítica de Foucault ao teor confessional da Psicanálise é um exemplo de genealogia histórica que relaciona, de maneira singular, dois mecanismos de constituição de uma "relação consigo mesmo", até então, aparentemente distintos, tanto em sua origem temporal quanto em relação ao 
sentido ou contexto de suas aplicabilidades: a confissão cristã e a prática psicanalítica.

Foucault remonta ao concílio de Trento, no século XVII, para marcar uma alteração no conteúdo descritivo das confissões. Anteriormente, se os fiéis, ao confessarem, eram incitados a descrever a cópula em seus mínimos detalhes: a "posição respectiva dos parceiros, as atitudes tomadas, gestos, toques, momento exato do prazer" (Foucault, 1976/1988, p. 22), a partir desse Concílio este enfoque foi desestimulado, revestindo o ato sexual sob um manto de obscuridade e de discrição, deslocando "o momento mais importante do ato em si para a inquietação do desejo, tão difícil de perceber e formular; pois que é um mal que atinge todo o homem e sob as mais secretas formas" (p. 23).

Neste sentido, "passou de uma problemática da relação para uma problemática da 'carne', isto é, do corpo, da sensação, da natureza do prazer, dos movimentos mais secretos, da concupiscência, das formas sutis da deleitação e do consentimento" (p. 102), por meio de "regras meticulosas de exame de si mesmo" (p. 23).

Desta forma, a confissão passa a ativar e a recriar "todas as insinuações da carne: pensamentos, desejos, imaginações voluptuosas, deleites, movimentos simultâneos da alma e do corpo, tudo isso deve entrar, agora, e em detalhe, no jogo da confissão e da direção espiritual” (p. 23).

É nesta direção que a psicanálise, segundo Foucault, comunga com o cristianismo do mesmo viés, presente no dispositivo confessional, que passa a considerar e a tratar o desejo como realidade obscura e portadora da verdade do sujeito.

Era o germe da passagem do dispositivo da aliança, que se centrava nas regras do matrimônio, as quais definiam a correção ou não das práticas sexuais, para o dispositivo da sexualidade, que vai deslocar a importância do ato para o momento que o precede, isto é, o da relação do indivíduo com tudo o que nele pode ser considerado de origem ou matéria sexual: então, o sexo passa a ser, primordialmente, uma questão do indivíduo consigo mesmo e, mais ainda, como lugar de sua verdade profunda. 
A partir dos códigos da aliança, a sexualidade emergia cada vez mais como realidade independente, passando da temática da carne para a temática do organismo, da temática do pecado para a da saúde. Inicialmente apoiada no dispositivo da aliança, que codificava a carne, hoje é o dispositivo da sexualidade que a sustenta.

A família é o espaço tenso dessa transição. Enquanto Charcot retirava da família (do seio da aliança, portanto) o paciente perturbado, para devolver-lhe um indivíduo sadio, Freud abandona o modelo neurológico e intensifica a psicologia das relações familiares. Descobre o "Édipo", com o qual o saber médico coloca em questão e ameaça a autoridade da lei da aliança, fundada na tradição. A ciência não recuava, então, diante do tabu do incesto, aproximando-se do fato para encontrar suas razões. E é assim que Freud descobre, com a universalidade da passagem do "Édipo", a necessidade de sua superação, sem o que a criança não se torna adulto, não realiza sua própria humanidade. Com isso, é a ciência da sexualidade, então, que legitima ou sustenta a lei da aliança.

A psicanálise surge no momento em que a burguesia aplicava a si, com mais rigor, o dispositivo da sexualidade, gerando os infortúnios que cabia à psicanálise explicar e aliviar com sua técnica.

Foucault baliza esse movimento do sexo na história ocidental por meio do jogo ou oscilação de três noções que o articulariam: desejo, ato e prazer. Em entrevista, Foucault diz que "a 'fórmula' cristã enfatiza o desejo e tenta erradicá-lo. Os atos têm que se tornar algo neutro; deve-se agir apenas para ter filhos ou para cumprir o dever conjugal. E o prazer é excluído tanto na prática quanto na teoria: 'desejo' - ato - 'prazer'. O desejo é praticamente excluído - o desejo tem que ser erradicado - porém, é teoricamente muito importante" (Dreyfus \& Rabinow, 1995, p. 268).

$\mathrm{Na}$ modernidade, o desejo é "teoricamente enfatizado e aceito na prática, uma vez que se tem que liberar o próprio desejo. Os atos não são muito importantes, e o prazer - ninguém sabe o que é!" (Dreyfus \& Rabinow, 1995, p. 268). Esta referência irônica ao prazer, na modernidade, aponta para o deslocamento estratégico no qual Foucault via a possibilidade 
de rompimento com o dispositivo da sexualidade. Não no sentido de um hedonismo fácil ou através da perspectiva reichiana, a qual, para ele, ainda fazia parte do próprio dispositivo da sexualidade, porque não rompia com a hipótese repressiva e, conseqüentemente, não era capaz de romper com o processo de subjetivação que o dispositivo produzia.

Para Foucault, o essencial é que "o homem ocidental há três séculos tenha permanecido atado a essa tarefa que consiste em dizer tudo sobre seu sexo" (Foucault, 1976/1988, p. 26).

Ora, o fio "intencional" que Foucault descobre sob esse impulso manifesto está atrelado ao que chama de bio-poder, a crescente necessidade histórica de controlar e disciplinar a vida. E a sexualidade cumpre estrategicamente essa função, ao permitir o acesso tanto ao que há de mais particular no indivíduo, quanto ao controle das populações.

Foucault dizia, mesmo, que pretendia fazer uma história da sexualidade como Marx havia feito a do capital, isto é, mostrar seus mecanismos de produção, e não apenas denunciar a exploração ou a repressão. Por isso diz, de forma geral, que o poder é produtivo, está muito mais ligado ao dizer "sim" do que ao dizer "não", às formas de produção do comportamento do que à sua negação.

O que não significa negar que haja repressão sexual, mas entender que o sexo faz parte de uma economia mais geral, em que os interditos encontram-se ao lado das estimulações para a produção de uma forma normalizadora, e que os interditos também são estimulantes e produtores de perversões. Nossa sociedade, diz Foucault, não deixou de roçar e de estimular cada vez mais a interdição do sexo, de jogar com ela. Por isso é materialmente perversa.

Para não citar apenas a proliferação da pornografia, era o que Charcot fazia com suas pacientes, produzindo a histeria no hospital; é o que o espaço da família nuclear burguesa favorece, com a intensificação dos afetos e o 
interdito sexual (complexo de Édipo), ou o difícil equilíbrio entre amor filial e sexual nesse contexto.

Mas o que Foucault frisa, nesse momento, é o caráter produtor $\mathrm{d}$ poder, que se oculta diante da tão propalada repressão.

Nossa forma de representação do poder ainda é a jurídico-discursiva, cuja ideologia representava a ascensão do Estado Moderno. É o modelo do Direito, da lei que proíbe, enquanto não pararam de proliferar mecanismos de controle e disciplina sobre os indivíduos, de técnicas de produção de comportamento. É a representação do poder soberano de tirar a vida, enquanto crescia o pudor de tirá-la e o poder se encarregava cada vez mais de gerir a vida.

É esse modelo que Foucault detecta também no interior da psicanálise, mesmo aquela que, ao contrário da hipótese repressiva mais simples, que entende o sexo como uma natureza bruta ou libertária que se choca com o poder externo, afirma que o poder está ligado intrinsecamente ao sexo, porque o constitui, uma vez que o desejo nasce da falta, instituída pela interdição - mais uma vez, por um "dizer" não. Como procuramos mostrar, é o modelo da guerra que Foucault entende mais adequado para a descrição dos jogos de poder.

Naturalmente, toda essa trama de força de sentidos não faz parte da consciência imediata de seus participantes (o padre, o fiel, o psicanalista e o paciente), o que leva Foucault a falar em uma história sem sujeito.

Essa "intencionalidade" longitudinal requer uma genealogia. Aos participantes, cabem as dúvidas e certezas de necessidades e estratégias locais do presente imediato ou futuro próximo. Enredados pelos dispositivos (com seus "corpos arruinados", na sentença crítica e pessimista de Foucault sobre o caráter disciplinador da modernidade), também podem assumir pontos de fuga nesse jogo instável de forças que representa o cotidiano da história.

4 Exceto o exemplo da pornografia, os outros são citados por Foucault (1976/1988), em História da Sexualidade I. 
Nesse sentido, embora tenha privilegiado em sua genealogia da sociedade moderna o caráter prisional do poder, a concepção foucaultiana de poder implica resistência e possibilidade de ultrapassamento do sentido das forças do dispositivo, cujos exemplos empíricos aparecem em suas entrevistas, quando questionado sobre o ultrapassamento do dispositivo da sexualidade pelo movimento gay ou feminista; sempre com a análise reticente e cautelosa - o que fez de Foucault um filósofo da suspeita, por excelência -, pois desse jogo instável de constantes rearticulações estratégicas das forças de poder, nada está ganho ou perdido definitivamente.

Em síntese, o que denominamos "sexualidade" não é nem uma emanação natural de força e de prazer, nem uma "realidade subterrânea que se apreende com dificuldade", como afirmam o cristianismo e a psicanálise, mas é

o nome que se pode dar a um dispositivo histórico (...) a grande rede da superfície em que a estimulação dos corpos, a intensificação dos prazeres, a incitação ao discurso, a formação dos conhecimentos, o reforço dos controles e das resistências, encadeiam-se uns aos outros, segundo algumas grandes estratégias de saber e de poder (Foucault, 1976/1988, p. 110).

Trata-se de um dispositivo histórico no qual, ironicamente, considerase "liberação" discursarmos sobre o sexo, através da hermenêutica do desejo, ao invés de praticá-lo criativamente como alavancamento de novas formas de subjetividade.

A radicalidade desta proposta foucaultiana afeta diretamente o setting terapêutico, pois aponta para a possibilidade de um tipo de controle sobre o corpo insuspeito na aparente liberdade da prerrogativa da "liberdade" de tudo dizer, ou aparente liberdade de um espaço dialógico no qual se pode encontrar o encaminhamento das insatisfações do indivíduo dentro dos quadros "normalizadores" da conduta historicamente constituída.

Assim, Foucault, ao desnaturalizar os discursos e as práticas problematizadoras do desejo e edificadoras do dispositivo da sexualidade, 
nos alerta para a rede de relações histórico-sociais que produzem e atravessam nossas identidades, pensamentos e possibilidades de interação.

Como consequiência, vemos que a personalização dos problemas existenciais sem a consideração da rede de forças sócio-históricas que a atravessam pode se revelar como instrumento de manutenção de determinada conformação de poder, particularmente nos ambientes privilegiados das intervenções psicológicas.

Isto ocorre na medida em que nem sempre as abordagens psicológicas participam da análise crítica dos próprios preceitos constituidores da identidade do indivíduo, já que a própria identidade do sujeito só faz sentido em conformidade com determinada realidade histórica na qual está imerso.

A esta atmosfera "normalizadora" da Psicologia e da Psicanálise foram remetidas constantemente as análises de Foucault.

\section{O diagnóstico foucaultiano das ciências da subjetividade}

Ao apontar para a conformação de discursos interiorizadores do indivíduo ("personalidade", "inconsciente", "consciência", "subjetividade", "psique"), Foucault nos oferece um instrumental para a visualização do processo de constituição do saber psicológico, conjugando-o ao desenvolvimento do bio-poder. Pois uma vez que o poder passa a investir sobre a vida, buscando extrair o máximo controle sobre os corpos, surge uma série de saberes encarregados de "sua natureza", "da subjetividade que o habita", seus costumes, moral etc.

Note-se bem, Foucault não faz do poder apenas ocasião para o desenvolvimento de certos saberes, mas os une intrinsecamente, de tal forma que, como dissemos, não é possível falar em saber puro ou desinteressado, pois todo saber também é efeito de uma prática de poder, uma forma de lançar nossos olhares sobre as coisas, um posicionamento estratégico do corpo em busca de, ou em reação ao poder, uma força fazendo frente a outras forças. 
Daí Foucault falar em produção, e não em descoberta da verdade, de que o método experimental da ciência seria apenas a sublimação mais acabada. Isto é, o modelo sujeito - objeto do conhecimento, que pressupõe a universalidade e neutralidade tanto de um quanto de outro; a possibilidade da repetição indefinida da experimentação, independente do tempo e do lugar, que liberou a verdade da idéia de acontecimento datado e com testemunhas privilegiadas; enfim, a possibilidade de um conhecimento intersubjetivo, bastando, para isso, o mesmo sistema de referências, esse que se coloca como neutro ou objetivo, liberando, assim, a verdade do jogo de coações ou manifestações misteriosas (como no caso dos processos da Inquisição ou da prática da alquimia na Idade Média). Tudo isso foi, sem dúvida, diz Foucault, o passo mais importante na história da verdade no ocidente (conferir, nesse sentido, “A casa dos Loucos”, Machado, 1979, pp. 113-128). Mas não se trata, com isso, de abraçar cegamente sua ideologia, e deixar de ver todo o regime prático-discursivo que sustenta o saber científico. Vale dizer, de passagem, que nos parece notória a proximidade de Foucault com as idéias de Khun. A caracterização do regime de saber por Foucault (1971/2000), em A Ordem do Discurso, é muito próxima da noção de paradigma, e é no mínimo curioso o silêncio de Foucault sobre a obra de Khun.

Mais ainda, se todo saber é inscrito como produção, nem todos têm o mesmo caráter de objetividade acima descrita. É o caso da psiquiatria, cuja crise, segundo Foucault, tem muito mais a ver com o questionamento desse modelo (sujeito - objeto) de conhecimento, do que com dificuldades empíricas particulares. O que está em jogo aí, diz Foucault, é o poder do médico sobre o paciente, é a dificuldade (mais teórica do que prática, como mostra a história) de transformar a loucura em objeto.

É sobre esse tipo de saber, que não se ajusta facilmente ao modelo de objetividade da ciência, que Foucault dirige suas "baterias" (o que não significa conferir inocência às ciências naturais).

Ora, esse é o caso das ciências humanas, cuja arqueologia (Foucault, 1966/1995) já revelara o caráter empírico - transcendental do seu objeto (o 
homem), isto é, a uma só vez passível de determinação empírica, portanto, de estudo positivo (determinado pela vida, pela linguagem e pelo trabalho), e condição do próprio objeto, sujeito da representação a que se encontra submetido 5 .

O que a genealogia descobre, assim, mais uma vez, é o caráter suspeito ou demasiadamente humano do objeto desses saberes. Em outros termos, que seus "objetos" não são objetivos no modelo vigente do saber científico e, portanto, são construções ilusórias na medida em que pretendem se passar ou valer por tal. É nesse sentido que Foucault diz que a noção psicanalítica de inconsciente não passa de uma construção histórica que tem início com o cristianismo "agostiniano", assim como sua crítica à idéia de "eu profundo", fundamentadora de muitas abordagens psicológicas.

A crítica de Foucault à noção de profundidade não visa apenas à psicanálise. É recorrente, em seus escritos anteriores à fase genealógica, a contraposição de seu método à hermenêutica em geral, que leva ao comentário interminável sobre um sentido vivido, que, por natureza, escapa por todos os lados, uma vez que ela pressupõe o excesso do significado sobre o significante.

A intenção da crítica não é negar a sedimentação de sentidos no corpo vivido - muito pelo contrário; não é negar, assim, uma "memória inconsciente" em tudo o que fazemos. O que está em jogo é uma topografia, uma forma de marcar e de agir sobre o relevo da subjetividade ou, simplesmente, sua própria concepção. No caso, a suspeita de Foucault de que o vínculo da noção de profundidade com a noção de interioridade seja marcado pela noção de "inconsciente", na psicanálise, ou pela noção de

5 Foucault (1966/1995), em As Palavras e as Coisas, tinha, naturalmente, uma perspectiva teórica bastante distinta daquela da fase genealógica. Em particular, Foucault apostava na lingüística - aplicada à etnologia e à psicanálise - para a superação das ciências humanas, ou para o desaparecimento do homem na história, cuja entrada foi essa, da dupla perspectiva de objeto e sujeito do conhecimento. Não cabe aqui discutir essas diferenças. 
"consciência", na hermenêutica. Vínculo este que determina a estratégia de seu enfrentamento, através da palavra ou interpretação.

Em Arqueologia do Saber, por exemplo, quando Foucault (1969/1997) expõe a necessidade de se dar conta do regime que comanda nossos discursos, ele afirma que sua elucidação não constituiria, "de maneira alguma, uma espécie de discurso secreto, animando, do interior, os discursos manifestos", e que "não é, pois, uma interpretação dos fatos enunciativos que poderia trazê-los à luz, mas a análise de sua coexistência, de sua sucessão, de seu funcionamento mútuo, de sua denominação recíproca, de sua transformação independente ou correlativa" (p. 33). Ou ainda, como diz em A Ordem do Discurso, acontecimentos discursivos "dispersam o sujeito em uma pluralidade de posições e funções possíveis” (1971/2000, p. 58), e é esse jogo que devemos descrever.

Por isso Foucault diz que tudo está à superfície, a saber, em todas as relações de sentido com o outro que nos constituem, e não em uma interioridade de difícil acesso, cuja noção, na verdade, também é regrada e instituída através de práticas sociais (do dispositivo da sexualidade, como dissemos).

Por isso, também, a questão é muito mais política do que de interpretação (hermenêutica), está muito mais no plano da ação e experimentação do corpo (que também fala), do que da ação das palavras nos limites do consultório, ou da regra do tudo dizer, mas apenas dizer, cuja transformação no encontro com o outro não cruza os limites do instituído, antes os reforça, independente da questão de se saber se a psicanálise cura ou não, se alivia ou não nossos infortúnios.

Em síntese, feito o diagnóstico do caráter ilusório dessas "ciências", abre-se a possibilidade da emergência de uma Ética na construção de nossas subjetividades, ou da liberação da política do corpo de toda normatização do saber que se pretenda científica.

Ora, esta transmutação do eu profundo em eu histórico, que certamente provoca uma reformulação da abordagem da Psicologia e de seus embasamentos epistemológicos, parece-nos propiciar, mais do que uma 
temida perda do seu objeto, o seu deslocamento, que ressalta a importância das práticas incidentes sobre o corpo, não só no setting terapêutico, mas em outros âmbitos de constituição de subjetividade, sejam eles os hospitais, as escolas, as creches, os quartéis, dentre outros.

\section{Postulados do Corpo e da Alma para uma metodologia do estudo e da prática da Psicologia}

A partir do exposto, diagramaremos alguns postulados da genealogia foucaultiana como forma de permitir uma melhor visibilidade do corpo histórico e de sua eventual aplicabilidade em Psicologia. Não pretendemos que esta diagramação seja sistemática, apenas queremos ressaltar aspectos ou perspectivas que se completam, mesmo correndo o risco de certa redundância.

À guisa de introdução, e de modo geral, o corpo é um elemento sobre o qual inúmeras correlações de forças incidem e se dispõem, atravessando-o e exercendo sobre ele uma série de conformações, dentro de um jogo de dominações e submissões, difuso e disperso em toda a rede social.

A alma histórica, enquanto elemento prático-discursivo de desenvolvimento e produção de formas que se aglutinam e se inscrevem sobre o corpo, é o depositante histórico de verdades que visam a um acesso direto sobre os corpos. Sendo a alma o depositante de verdades e de discursos, o corpo é, por sua vez, o depositário de marcas e de sinais que nele se inscrevem e que nele se cravam, de acordo com as efetividades de tais embates, que têm em tal corpo seu "campo de prova" e de constante confirmação e exercício.

A corporeidade é o elemento de visibilidade de tais defrontamentos: seja no seu efeito acumulativo histórico (enquanto superfície de inscrição de marcas e de sinais); seja nas suas conformações presentes, nos quais a fugacidade do momento presente manifesta o registro instantâneo destes embates; seja na sua antevisão prospectiva - em termos de antecipação de novas articulações futuras, propiciadoras de novas redisposições estratégicas dos corpos e das almas, efetuada pelo efeito de conjunto de tais embates, em 
toda a rede social; seja no sentido de afirmação da submissão a certo tipo de dominação; seja no sentido de resistência a tais forças.

O corpo, para Foucault, é, portanto, elemento de sedimentação, sujeito às marcas e aos sinais físicos decorrentes de amplas séries de processos históricos, e a alma o depositante de sedimentação, de confrontação e de dinamização de uma série de campos de verdades historicamente constituídos, e em constante embate.

Mas é muito importante frisar que, se do ponto de vista estratégico das forças de saber e de poder, corpo e alma são para Foucault diferenciados, é porque a alma se mostra como mecanismo de acesso ao corpo. Eé apenas deste ponto de vista bélico-estratégico que é possível fazer tanto distinções entre corpo e alma na obra de Foucault, como também estabelecer Postulados para a compreensão desta dinâmica.

Assim, trata-se de desnaturalizar tanto as marcas físicas dos corpos como suas emanações anímicas microfísicas, pois ambas só podem ser discernidas enquanto emersas em um jogo de correlações de forças históricas que as constitui.

No entanto, nem todas as marcas e sinais depositados sobre os corpos dos indivíduos emergem enquanto um campo de significação e de sentidos consolidados pelo exercício dos saberes/poderes. Estas sinalizações podem ainda estar atuando sobre os corpos de maneira incipiente, difusa, residual ou extremamente fragmentada, em termos da constituição estratégica de suas "verdades" sobre as corporeidades.

Para esclarecer esta importante diferença destacamos o Postulado da Inscrição sobre o corpo dos poderes/saberes, no sentido de cravar no corpo um sinal, um estigma, um padrão, uma medida, uma assinatura de uma conformação de "verdades" (seja ela prisional, sexual, disciplinar, de exclusão, política, estética, científica, artística, dentre outras).

Ou seja, as tipificações psicológicas subjetivadoras são mais externas do que muitas correntes psicológicas compreendem, e só têm sentido consideradas de acordo com certo diagrama histórico de forças que as fazem 
emergir: são cravamentos científicos sobre o corpo, vindos de "fora" desta corporeidade.

Neste sentido, destacamos o Postulado da Transversalidade para enfatizar que o corpo é atravessado por múltiplas redes de forças (de higienização, de disciplinamento, de sexualização, de medicalização, de psicologização dos indivíduos, dentre outras), no processo de constituição de "verdades" sobre ele focalizadas. Com isto, dissolve-se a noção ingênua de que um corpo livre de amarras diretamente físicas estaria isento da incidência de amplos mecanismos de controle e de dominação.

É por meio do Postulado da Transversalidade que podemos tornar mais visível a correlação corpo/alma em sua inserção em determinada rede múltipla de saberes/poderes.

Estas articulações de forças atravessando os corpos visam a dispô-los dentro de determinada estratégia de poder, por meio do direcionamento de seus impulsos, vontades, sensações ou sentimentos. Sob este prisma, o corpo é foco de disposição (Postulado da Disposição), compreendida enquanto uma tecnologia de produção e ordenação material-discursiva de seus sentidos.

É este caráter disposicional do corpo que possibilita a constituição de uma série de dispositivos históricos, dentre eles, o dispositivo da sexualidade.

A noção de dispositivo é esclarecida em entrevista por Foucault:

Trata-se de um conjunto heterogêneo que engloba discursos, instituições, organizações arquitetônicas, decisões regulamentares, leis, medidas administrativas, enunciados científicos, proposições filosóficas (...) o dispositivo é a rede que se pode estabelecer entre estes elementos (...) entre estes elementos, discursivos ou não, existe um tipo de jogo, mudanças de posição, modificações de funções (...) é uma formação que em determinado momento histórico teve como função responder a uma urgência. $O$ dispositivo tem, portanto, uma função estratégica dominante (Machado, 1979, p. 244).

Mais ainda:

... engloba um duplo processo: por um lado, processo de sobredeterminação funcional, pois cada efeito, positivo ou negativo, desejado ou não, estabelece uma relação de ressonância ou de contradição com os outros; por outro lado, é um 
processo de perpétuo preenchimento estratégico. (...). É isto, o dispositivo: estratégias de relações de força sustentando tipos de saber e sendo sustentadas por eles (pp. 245-246).

Vale frisar que, nesse sentido, à diferença de As Palavras e as Coisas (1966/1995) ou Arqueologia do Saber (1969/1997), o importante é frisar, agora, que as formações discursivas são desenvolvidas em práticas sociais, ao contrário de fundá-las.

É justamente para enfatizar a complexa correlação entre corpo e dispositivo em sua multiplicidade de elementos e forças, que destacamos este postulado, pois o intuito primordial da sociedade normalizadora, mais do que reprimir a conduta do indivíduo, é influenciá-lo, conduzi-lo e inclinálo, por meio de mecanismos dispositivos, no sentido de submeter determinada posição de corpos a certos acessos históricos de saberes/poderes.

Daí podermos também falar em Postulado da Posição do Corpo na rede de saberes/poderes, enquanto efeito microfísico desse processo disposicional, de forma que a constituição da subjetividade do sujeito moderno possui caráter topológico.

Este é um dos aspectos centrais de diferenciação da genealogia foucaultiana de diversos contextos da Psicologia, os quais partem, principalmente em certas abordagens psicopatológicas, da premissa de um acesso exclusivamente tipológico sobre o corpo dos indivíduos submetidos a tais saberes.

Tipificar o sujeito psicológico como "louco", "normal", "anormal", "homossexual", "perverso" etc., mais do que relevar ou reconhecer sua "natureza", é dar-lhe um lugar social, inserindo-o numa rede de agenciamentos e de discursos para seu controle ou percepção estratégica de suas mutações e de seus deslocamentos constantes a partir daí.

É por isto que a genealogia foucaultiana é disposicional e topológica, enquanto arte de ordenar os fenômenos corpóreos sob uma ótica da estratégia de forças e de saberes, ao mesmo tempo, exteriores e transversais, já que transpassam os corpos, interpenetrando-os de história. 
Por último, e à guisa de conclusão, é possível reconhecer o caráter tensionado desses mecanismos - Postulado da Tensão dos Embates entre corpos/poderes/saberes -, na medida em que todo esse processo não é referente a uma (re)disposição do corpo enquanto mero receptáculo passivo destas forças, mas enquanto embate de tais forças em constante afrontamento através da corporeidade.

É possível ver, nesse sentido, as forças e a alma também como emergindo do próprio corpo, como sua manifestação frente às outras forças e almas que nele se inscrevem ou pretendem se inscrever.

Alma e corpo, portanto, são apenas termos dessa dinâmica tensa entre forças e formas de sentido em constante embate e formação.

Não podemos desconsiderar, assim, a coexistência do postulado da tensão, com a potencial emergência de múltiplas disposições resistenciais no contexto desta rede de forças, o que impede considerar o corpo apenas como suporte ou ponto de apoio, sendo então melhor considerá-lo como destino e foco da atuação desses enfrentamentos.

Se, em sua genealogia, o corpo aparece, sobretudo, como lugar de inscrição da alma, é porque Foucault assumiu mais a perspectiva do poder sobre o corpo, a história de sua dominação (ou aquilo que fizeram com nosso corpo na história), do que a perspectiva do corpo próprio, de seu caráter produtor ou de resistência.

Foucault se coloca, assim, em Vigiar e Punir (1975/1996) e História da Sexualidade I (1976/1988), do lado de fora da experiência do corpo próprio, porque estava interessado, sobretudo, na lógica do poder sobre o corpo ou no sistema de forças e saberes que o atravessam.

\section{Conclusão}

A este mapeamento das disposições do corpo e da alma, por meio de saberes/poderes historicamente constituídos, denominamos, para fins metodológicos, cartograma genealógico do corpo e da alma. 
O objetivo deste cartograma é compreender o fenômeno corpóreo do ponto de vista bélico-estratégico, que se refere à sua disposição num jogo de forças, com o intuito de edificar a genealogia da sua ocorrência, importância, movimentação e evolução, a qual pode se projetar em macromomentos históricos.

É o que nos permite compreender a alma moderna, não como emanação ou essência metafísica do corpo, mas como instrumento construído historicamente, com intuito de diagnóstico - constitutivo de um saber - e de intervenção estratégica - enquanto exercício de poder.

Não há interioridade a ser desvelada, mas apenas a necessidade fundamental de visualizar os deslocamentos dos corpos e almas nas práticas discursivas ou as estratégias de poder sobre a microfísica de cada indivíduo. Sobretudo, o enfoque foucaultiano não tem caráter ontológico de descoberta da "natureza" do que venha a ser o corpo e a alma, ou seu caráter "essencial". Mas é um instrumental para a análise bélico-estratégica das forças presentes em um campo de batalha discursivo, e não só discursivo, mas também material, na constituição e sucessão do corpo e da alma na história.

Dessa forma, destacamos a aplicabilidade transdisciplinar da analítica corpóreo-anímica de Foucault, em especial no contexto específico da Psicologia, no sentido de sensibilizar seus estudiosos para a constituição sócio-histórica de uma série de conceitos psicológicos que são anexados "animicamente" aos corpos dos indivíduos.

Acreditamos que, a partir da concepção de corporeidade atravessada de história, cartografada genealogicamente e relevada por meio dos Postulados aqui apresentados, seja possível instrumentalizar a Psicologia com uma analítica sobre os mecanismos de poder e de saber que atuam sobre os indivíduos e que a atravessam enquanto ciência humana. Ou seja, contribuindo para dar maior relevância ao corpo historicamente constituído, certamente a genealogia de Foucault nos previne contra tendências psicologizantes que ignoram o enredamento do indivíduo na história. Assim, pode servir de orientação sobre o relevo histórico (prático-discursivo- 
epistemológico) no qual a Psicologia emerge constante e movediçamente, já que ela é um saber que dispõe de um acesso privilegiado aos corpos através da "alma", em constante embate e produção de significações, sentidos e subjetivações.

Silveira, F. A., \& Furlan, R. (2003). Body and soul in Foucault: Assumptions for a methodology of psychology. Psicologia USP, 14(3), 171-194.

\begin{abstract}
Michel Foucault's work sets in figure the body as an expression of a whole set of powers and knowledge, which are strategically articulated within the history of Western Society. The body is, simultaneously, an agent and a piece within the forces interplay present in all social net, turning out to be a depositary of marks and signs that get engraved in it. This happens as a result of those interplays and clashes, which, in turn, have in corporality its test-field. And the soul emerges as instrument of the powers / knowledge performance over the body, in the process of constitution of the subjects' historical body. The objective of this paper is to develop postulates related to Foucault's body and soul notions, for investigation and practice in Psychology.
\end{abstract}

Index terms: Foucault, Michael, 1926-1984. Body. Soul. Subjectivation.

Silveira, F. A., \& Furlan, R. (2003). Corps et âme chez Foucault: Postulat pour une méthodologie de la psychologie. Psicologia USP, 14(3), 171194.

Résumé: Michel Foucault identifie le corps comme l'expression de pouvoirs et de savoirs qui s'articulent stratégiquement dans l'histoire de la société occidentale. Le corps est, simultanément agent et pièce dans un jeu de force présent dans toute la chaîne sociale, qui le trend dépositaire de marques et de signaux qui s'inscrivent par des chocs, qui ont dans la corporalité son « champ de preuve ». Et l'âme apparaît comme un instrument d'action des pouvoirs/savoirs sur le corps, dans le processus de constitution du corps historique des sujets. L'objectif de ce travail est de 


\section{Fernando de Almeida Silveira e Reinaldo Furlan}

développer des postulats sur le corps et l'âme chez Foucault, pour l'étude et la pratique de la psychologie.

Mots-clés: Foucault, Michel, 1926-1984. Corps. Âme. Subjectivité.

\section{Referências}

Defert, D., \& Ewald, F. (Org.). (1994). Dits et écrits - IV. Paris: Gallimard.

Deleuze, G. (1988). Foucault (C. Sant'Anna Martins, trad.). São Paulo: Brasiliense.

Dreyfus, H., \& Rabinow, P. (1995). Michel Foucault: Uma trajetória filosófica (V. P. Carrero, trad.). Rio de Janeiro: Forense Universitária.

Foucault, M. (1988). História da sexualidade I: A vontade de saber (11a ed., M. T. da Costa Albuquerque \& J. A. Guilhon Albuquerque, trads.). Rio de Janeiro: Graal. (Trabalho original publicado em 1976)

Foucault, M. (1995). As palavras e as coisas (7a ed., S. T. Muchail, trad.). São Paulo: Martins Fontes. (Trabalho original publicado em 1966)

Foucault, M. (1996). Vigiar e punir: Nascimento da prisão (14a ed., L. M. Pondé Vassallo, trad.). Petrópolis, RJ: Vozes. (Trabalho original publicado em 1975)

Foucault, M. (1997). Arqueologia do saber (5a ed., L. F. B. Neves, trad.). Rio de Janeiro: Forense Universitária. (Trabalho original publicado em 1969)

Foucault, M. (2000). A ordem do discurso (6a ed., L. F. de A. Sampaio, trad.). São Paulo: Loyola. (Trabalho original publicado em 1971)

Machado, R. (Org.). (1979). Microfísica do poder. Rio de Janeiro: Graal. (Edição com base em textos de Michel Foucault)

Silveira, F. A. (2001). Michel Foucault e a constituição do corpo e da alma do sujeito moderno. Dissertação de mestrado, Faculdade de Filosofia, Ciências e Letras de Ribeirão Preto, Universidade de São Paulo, Ribeirão Preto, SP.

Recebido em 10.04.2003

Aceito em 08.10.2003 